\title{
Fluorescent Lamp Modelling and Electronic Ballast Design by the Support of Root Placement
}

\author{
Ibrahim Aliskan*†, Ridvan Keskin* \\ *Department of Electrical and Electronics Engineering, Faculty of Engineering, Bulent Ecevit University, 67100 Zonguldak, \\ Turkey \\ (ialiskan@beun.edu.tr, ridvan.keskin@beun.edu.tr) \\ ${ }^{\ddagger}$ Corresponding Author: Ibrahim Aliskan, Department of Electrical and Electronics Engineering, Faculty of Engineering,
Bulent Ecevit University, 67100 Zonguldak, Turkey, Tel: +0903712911570 , Fax: +903722574023 , ialiskan@ beun.edu.tr
}

Received: 28.07.2016 Accepted: 02.09.2016

\begin{abstract}
It is presented that high frequency electronic ballast for fluorescent lamps is designed with root placement method using natural frequency and damping ratio. Also, a fluorescent lamp is designed as to have dynamic resistant. The method proposes simple mathematical calculations instead of complex mathematical calculations and the approaches based one of the component of resonant tank, which arbitrary chosen value. Also it is capable to provide accurate values, which can be employed in new types to ballasts. Natural frequency and damping ratio, which are parameters of the method, are chosen switching frequency, 0.707, respectively. Transfer function of electronic ballast circuit is calculated by means of proposed method. After that, components of the circuit are find out. $220 \mathrm{~V}(\mathrm{rms})$ voltage was achieved at ignition and obtained $30 \mathrm{~W}$ lamp power in state space operation. Electronic ballast design and a fluorescent lamp are made of using Matlab/Simulink interface and the results are presented.
\end{abstract}

Keywords Electronic ballast, design parameters, switching frequency, fluorescent lamp.

\section{Introduction}

Humankind is always in the search of new energy sources and efficient use of current sources in view of the limited energy sources in earth. The economic crisis in the world in last years has shown that energy saving concerns has to consider to preserve natural resources. Many new developments have been applied to the traditional electrical equipment to improve the efficiency. Efficient usage of electricity, as a transformation phase of different energy types, has more importance. One of the most widely used fields of electricity is lighting. The most widely used light sources are incandescent and fluorescent lamps in lighting [1]. Even light bulbs are considered as the prior source of lighting, in 20th century, fluorescent lamps are developed to efficiently use energy. Usage of florescent bulbs in schools, offices and other places made the development of more efficient fluorescent lamps a necessity [2].

Fluorescent lamps or fluorescent tubes use electricity for heating mercury and vaporing through filaments to produce light. Light is produced after many phases in fluorescent lamps to be created after thermal radiation. When you turn on the electricity, it goes through the one electrode to another in the fluorescent lamp. When the initial voltage reached, mercury is vaporized and ultraviolet lights are emitted. By the help of phosphorus placed in tube, this ultraviolet light transforms to the emitted light to be seen by our eyes [3].

Fluorescent lamps have many advantages in comparison with regular bulbs. They are more expensive but have more than 10 times long life than regular bulbs. Because light is emitted from a larger source (not a single point like light bulbs) in florescent lamps, it emits more light. Blue light emitted by florescent bulbs are better for the eye comfort. An $18 \mathrm{~W}$ fluorescent lamp can emit light as much as a $75 \mathrm{~W}$ regular light bulb. It means that fluorescent lamps consume less energy and emit more light, which ends up in around $75 \%$ energy efficiency. In addition that, as the ballasts used in florescent lamps are developed, it is expected to increase their efficiency [4], [5], [6].

The ballast works as a part of a florescent lamp to reach starting voltage and to limits the current in the lamp terminals upon reached steady state. As the gas discharge starts, at 
ignition, current continuously increases and lamp voltage decreases. If resistance of the lamp is formulized as $R_{\text {lamp }}=d V / d I$, it is seen that the resistant has a negative slope or the lamp has negative resistance character (NTC). This requires the current to be limited. In less powered lamps, to limit the current, serial resistances may be used. However, this causes to loss power. Therefore, using ballast is a better way to save energy. There are two main type ballasts as electromagnetic ballasts and electronic ballasts [3].

Inductive ballasts, which named as magnetic or electromagnetic, are made of core rounded with aluminium or copper. In a fluorescent lamp, network voltage of $220 \mathrm{~V}$ is not enough to start lighting in the beginning. It requires around $300 \mathrm{~V}$ for starting firing. Therefore, an auxiliary device is necessary to generate high breakdown voltage for start-up and to stabilize lamp current. This device is the "starter" as a switch and used in the lamps to start lighting in the beginning. It does not work during the regular working or steady state times of fluorescent lamps.

Electronic ballasts require higher frequency than magnetic ballasts $\left(f_{e}>20 \mathrm{kHz}\right)$. They do not require a starter to initiate start-up voltage. In other words, they can give the start-up voltage themselves. Electronic ballasts are 10-20\% more efficient than the inductive ballasts [7]. When more lamps are used in a system, this efficiency becomes more important. The more efficient on lighting systems the less heat is emitted. It is listed below that advantages of electronic ballasts in compared with inductive ballast:

Increases the effectiveness of the lamp and all lighting system.

$>$ Prevents light vibration and stereoscopic events.

Increases power factor and does not need compensation.

Enables to use light current in any degree.

With lower heat increase, heat loss is decreased too.

Does not have noises.

$>$ Two lamps can work through a ballast.

$>$ Small size, less weight, high frequency [8] - [13].

In recent years, there has been quite works and researchers are studying about this topic. These works are about design to boosts efficiency and gain of electronic ballasts. As so the works based on lamp arc, it exists that based on one of the components of the circuit as well. These high-frequency fluorescent lamp models are used for optimization studies [3], [4], [5], [14], [15], [16], [17]. However, they are not enough finding components of the circuit and procuring optimum efficiency on account of the fact that it is not to calculate properly the components. In addition, Methods of them are based on one of the component of the resonant tank, which arbitrary chosen value, or to have complex resolutions.

In this study, circuit parameters and components of electronic ballast are calculated by using this method. The design is made with Matlab/Simulink interface. Natural frequency and damping ratio, which is parameters of the method, is chosen as natural frequency is switching frequency and damping ratio is 0,707 with the purpose of optimum efficiency [18]. Also it is focused on the design of an optimum resonant tank by considering the lamp equivalent resistant $R_{\text {lamp }}$ is variable at high frequency. Using this method increases the gain and efficiency of the circuit by means of calculate components of circuit exactly.

The paper divided into five sections. In section 2 , the fluorescent lamp resistance is designed as dynamic resistance model. Instead of voltage and current parameters, power of the fluorescent lamp is considered as a parameter in this approach. In section 3, design of the electronic ballast is presented. In section 4, the simulation study is presented. In section 5 , the results are shared.

\section{Fluorescent Lamp Model With Dynamic Resistant}

Circuit topology of a basic high frequency electronic ballast system is shown in Fig. 1. While it is supplied by dc power supply, there is no need for power factor corrector (PFC) circuits and the circuits to prevent total harmonic distortion (THD). The parallel resonant inverter behaves like a current source, which can be used to stabilize fluorescent lamp current [19].

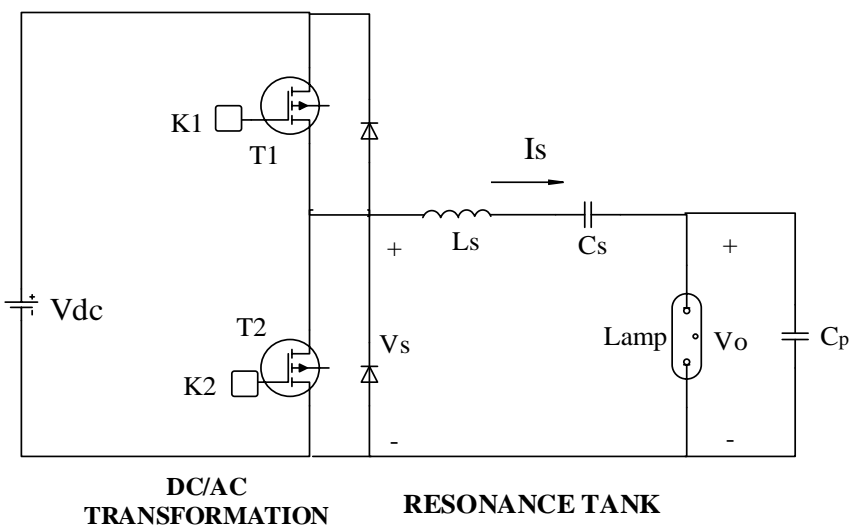

Fig. 1. Basic circuit configuration of an electronic ballast with half bridge series-resonant parallel-loaded inverter

While the circuit is suppling by dc battery, sinusoidal signal is obtained at desired high frequency level by use of T1 and T2 Mosfets, active power switches. This active power switches supplied with K1 and K2, square waves generators, are turned on and off alternately with a short dead time to drive the load resonant circuit at a high frequency. The parallel branch of resonant tank consists of a parallel capacitor, $\mathrm{C}_{\mathrm{p}}$, and a fluorescent lamp. Lamp Series branch of the circuit is formed by an inductor, $\mathrm{L}_{\mathrm{s}}$, and a capacitor, Cs. $\mathrm{C}_{\mathrm{p}}$ is to provide a sufficiently high voltage across the lamp terminals during starting transient, afterwards a proper ac current at the steady state [20].

When lamp is off state, it behaves like an open circuit, resistant of lamp is almost equal to infinite value due to mercury mixture which is in fluorescent lamp tubes. However, the mixture is ionized and the resistant value decrease swiftly when the lamp is on state. Therefore, the 
studies calculated resistant of lamp as a constant or with $R=V / I$ equation is not given proper calculation [4].

Various dynamic resistant approaches are developed to calculate resistant of fluorescent lamps [4]. The approaches based on voltage and current of the lamps are not given expected results due to the lamp resistant behaves as (NTC). That's why in this paper an approach based on lamp power to calculate resistant of the lamp is focused. A monotonic double exponential model is chosen to represent the electric characteristics of the lamp at high frequency optimally.

$$
R_{\text {lamp }}=a \cdot e^{(\text {b.Plamp })}+c \cdot e^{(\text {d.Plamp })}
$$

This equation is derived from a curve fitting to the experimental data of equivalent resistance versus average power [21]. A curve of equivalent resistance versus average power is presented in Fig. 2 as a consequence of simulation made in Matlab/Simulink.

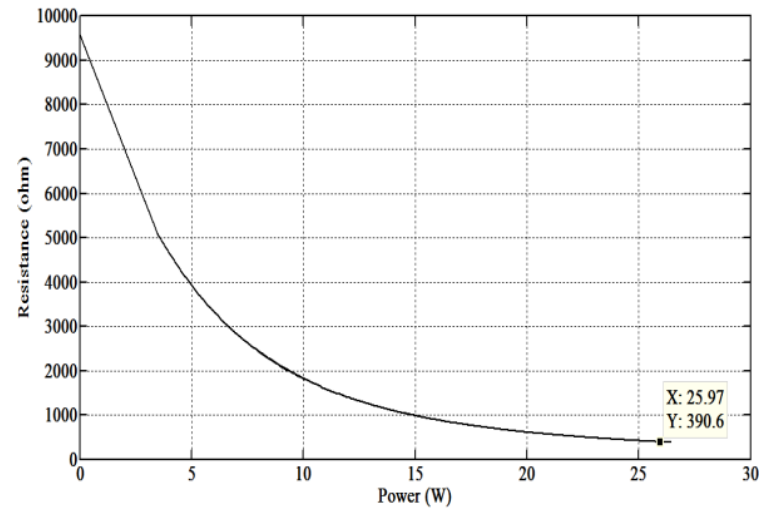

Fig. 2. Curve of Lamp resistant versus Average power in Simulink

\section{Electronic Ballast Design}

The purpose is to find values of the circuit parameters with mathematical calculation instead of based on one of circuit parameters or set value. By using this method, we find the parameter optimally. The control parameter used to vary the output power in all single stage topologies is switching frequency. These are variable frequency methods that higher frequency results in lower power delivered to the lamp [14]. First, damping ratio and switching frequency is chosen 0.707 , $56.82 \mathrm{kHz}$, respectively. Then transfer function of circuit is find out. Poles and zeros of the function is calculated. System identification is evaluated by using transfer function of the circuit.

Table 1. Parameters of the circuits

\begin{tabular}{|c|l|c|}
\hline$\zeta$ & Damping ratio & 0.707 \\
\hline $\mathrm{w}_{\mathrm{n}}$ & Natural frequency & $358.14 \mathrm{k} \mathrm{rad} / \mathrm{s}$ \\
\hline $\mathrm{s} 1$ & A root of the transfer function & $(-2.53+2.53 \mathrm{i}) .10^{5}$ \\
\hline $\mathrm{s} 2$ & A root of the transfer function & $(-2.53-2.53 \mathrm{i}) .10^{5}$ \\
\hline $\mathrm{s} 3$ & A root of the transfer function & $-3.58 .10^{5}$ \\
\hline $\mathrm{L}_{\mathrm{s}}$ & Series inductor & $1.31 \mathrm{mH}$ \\
\hline $\mathrm{C}_{\mathrm{s}}$ & Series capacitor & $14.4 \mathrm{nF}$ \\
\hline $\mathrm{C}_{\mathrm{p}}$ & Parallel capacitor & $2.97 \mathrm{nF}$ \\
\hline
\end{tabular}

Transfer function of the circuit indicated in Fig. 1 is find by following steps which is below and its poles are named as s1, s2, s3. After that, parameters of the circuit are calculated in consequence of committed calculations using natural frequency and damping ratio. As for gain of circuit, numerator of (3) must be maximize. Electronic ballast parameters are presented in table- 1 in accordance with this foresight.

$G(s)=V_{0} / V_{s}$

$i w L s=X L s$

$1 /\left(i w C_{s}\right)=X_{C s}$

$1 /\left(i w C_{p}\right)=X_{C p}$

$V_{0}=i(s) \cdot\left(\frac{X_{C p} \cdot R_{l a m p}}{\left(X c_{p}+R_{l a m p}\right)}\right)$

$V_{s}=i(s) \cdot\left(X_{L s}+X_{C s}+\frac{X C p \cdot R l a m p}{(X c p+R l a m p)}\right)$.

Equation (6) is divided by equation (7) or from voltagedivide law,

$\frac{V_{0}}{V s}=\frac{R_{\text {lamp }}+\frac{1}{i w C_{s}}}{i w L s+1 /(i w C s)+(\text { Rlamp }+1 /(i w C p))}$

then transfer function of the circuit is found out as a third order function in s-domain.

$$
G(s)=\frac{\frac{s}{C_{p} \cdot L_{s}}}{s^{3}+\frac{s^{2}}{C_{p} \cdot R_{\text {lamp }}}+\frac{\left(C_{p}+C_{s}\right) \cdot s}{C_{p} \cdot C_{s} \cdot L_{s}}+\frac{1}{C_{p} \cdot C_{s .} \cdot L_{s . R} \text { Rlamp }}}
$$

The circuit is stable because all of poles are located left side of s-domain. As to the zero of transfer function, locates at origin owing to structure of circuit. These circumstances can be seen from the transfer function. However, the gain was interfered by way of coefficient of the zero.

Open representation of fluorescent lamps is shown in Fig.3. $R_{\mathrm{f}}$ resistance represents filaments of lamps situated at terminals of the lamps. The resistance value is chosen using experimental data [15].
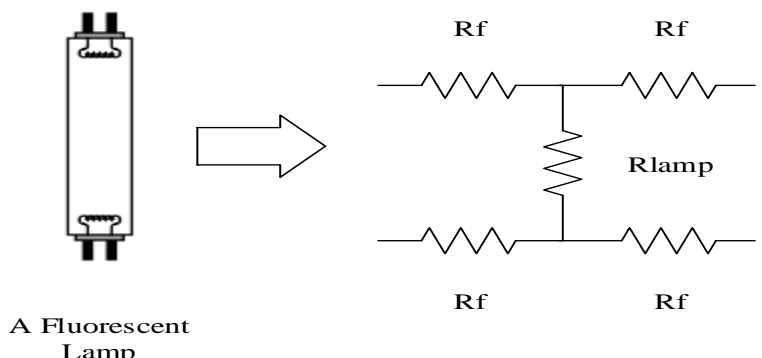

Fig. 3. Representation of a fluorescent lamp with filament resistances 


\section{Simulation Implementation of Fluorescent Lamp Model}

The goal is to make simulation study ideally to comprehend behaviour of fluorescent lamp system shown in Fig.1. Matlab/Simulink interface is used as computer environment to implement the complex circuit easily.

Applied circuit is presented in Fig.4. It is supplied with battery to have $220-240 \mathrm{~V}$. The mosfets are triggered with 0.5 fill rate by using a logical gate and a pulse generator. Also, they supply the resonance tank. Dynamic resistant model of the fluorescent lamp which is subsystem of Fig.4 is presented in Fig.5 clearly. Equation 1 is simulated using a function block parameter. A Controlled current source is used to execute dynamic resistant model. $\mathrm{R}_{\mathrm{f}}$ represents a filament resistance of the fluorescent lamp shown in Table 2. In addition, other data used in Fig.4 and parameters of the monotonic double exponential function is shown in Table 2 as well.
Table 2. Monotonic double exponential function parameters and other values

\begin{tabular}{|l|l|l|}
\hline Parameter & Explanation & Value \\
\hline $\mathrm{a}$ & Value of variable & 8147 \\
\hline $\mathrm{b}$ & Value of variable & -0.2113 \\
\hline $\mathrm{c}$ & Value of variable & 1433 \\
\hline $\mathrm{d}$ & Value of variable & -0.5353 \\
\hline $\mathrm{R}_{\mathrm{f}}$ & Resistanceof filaments & $6 \Omega \times 4$ \\
\hline $\mathrm{V}_{\mathrm{dc}}$ & DC Voltage & $236 \mathrm{~V}$ \\
\hline $\mathrm{f}_{\mathrm{s}}$ & Switching frequency & $56.82 \mathrm{kHz}$ \\
\hline$\left|\mathrm{I}_{\mathrm{in}}\right|$ & Amplitude of the current (Iin) & $0.26 \mathrm{~A}$ \\
\hline$\left|\mathrm{V}_{\text {in }}\right|$ & $\begin{array}{l}\text { Amplitude of input voltage } \\
\text { (Vin) }\end{array}$ & $236 \mathrm{~V}$ \\
\hline $\mathrm{R}_{\text {lamp }}$ & $\begin{array}{l}\text { Equivalent resistance of the } \\
\text { lamp }\end{array}$ & $389 \Omega$ \\
\hline $\mathrm{P}_{\text {lamp }}$ & Power of the lamp & $26.1 \mathrm{~W}$ \\
\hline
\end{tabular}

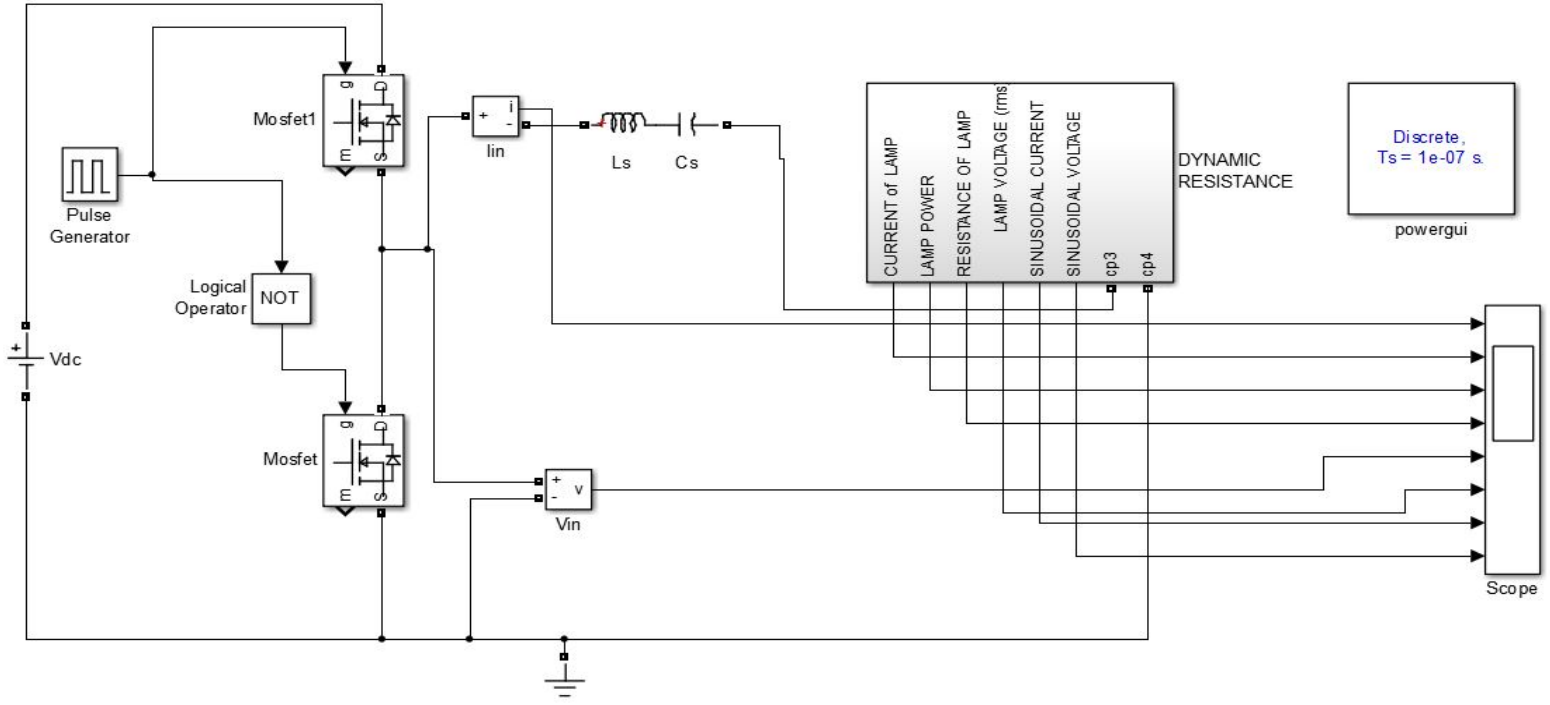

Fig. 4. A high frequency electronic ballast circuit with a dynamic resistant fluorescent lamp model

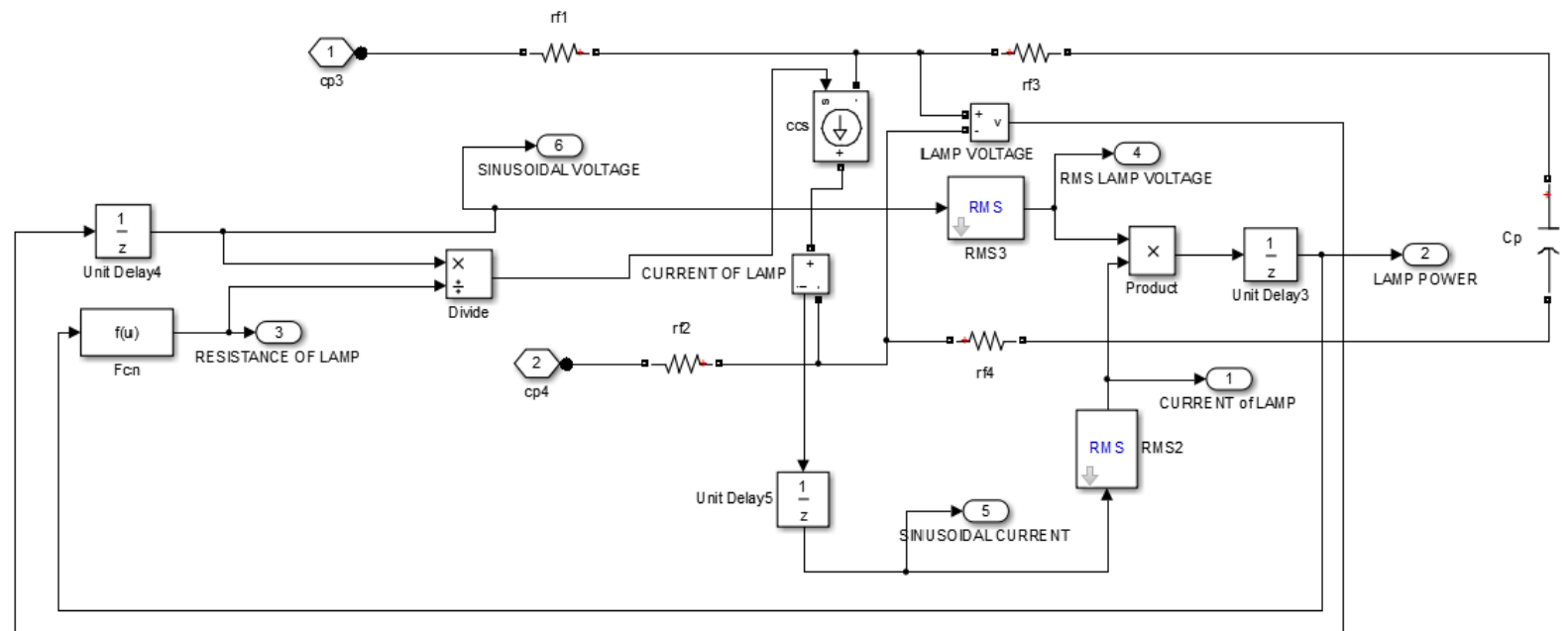

Fig. 5. Demonstration of dynamic resistant and the fluorescent lamp model 


\section{Results}

High frequency electronic ballast with dynamic resistance fluorescent lamp model, presented in Fig.4, whose subsystem is shown in Fig.5, is run. The results are presented in following figures. To design the circuit Matlab/Simulink is used.

Lamp voltage and current are presented with general overview in Fig.6, with root mean square forms. It is seen clearly that Lamp voltage is high at transient response because of the reason mentioned in section 1 . This means that, the lamp can be run and the resistance model is successful. In addition, before ignition, the lamp pretends open circuit because its resistant equals to roughly infinite value. Then in the ignition the current increases sharply due to decreasing of the resistant. This can be comprehended by means of reviewing to Eq .1. Finally, the current is suitable value in steady state operation.
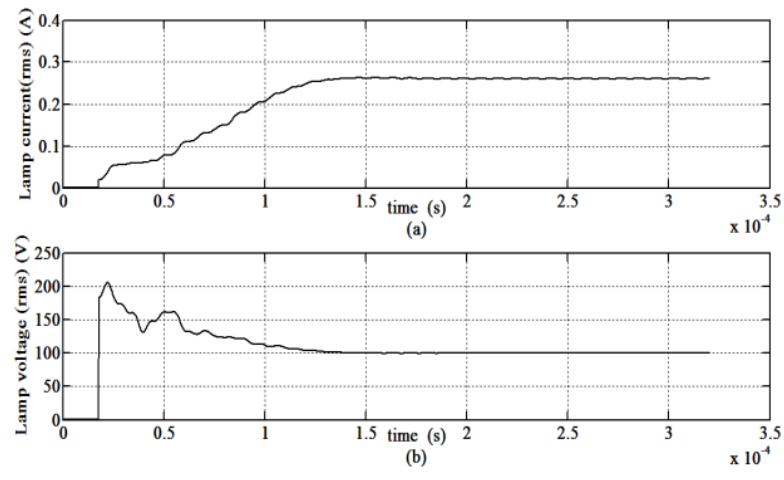

Fig. 6. Lamp Voltage and current versus time (a) Lamp current vs time (b) Lamp voltage vs time

Figure 7 is presented to better understand the relationship of lamp voltage and current at ignition. On the other hand, there is a lamp dynamic resistance variation $\left(r_{\text {lamp }}=\Delta V_{\text {lamp }} / \Delta I_{\text {lamp }}\right)$.

Voltage and current waveforms of the lamp in lamp running is presented in Fig.8, with sinusoidal waveforms. It can be seen that phase difference between them nearly equal to zero. Thus ensuring that the lamp represents a pure resistive load with high linearity at high operating frequency. Also they have no fluctuations.

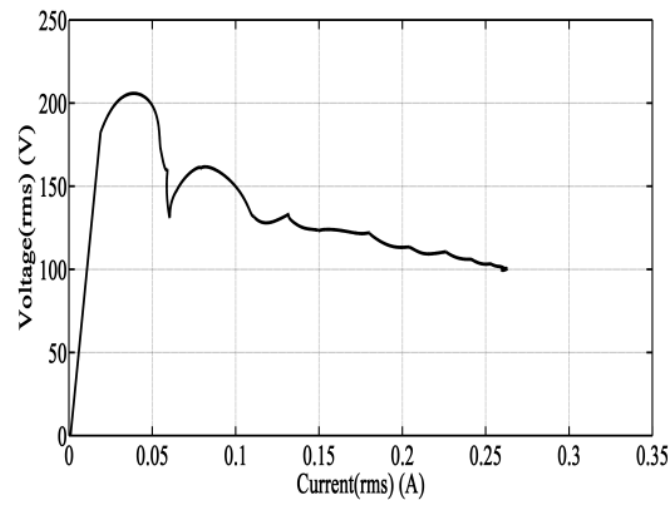

Fig. 7. Lamp voltage versus lamp current

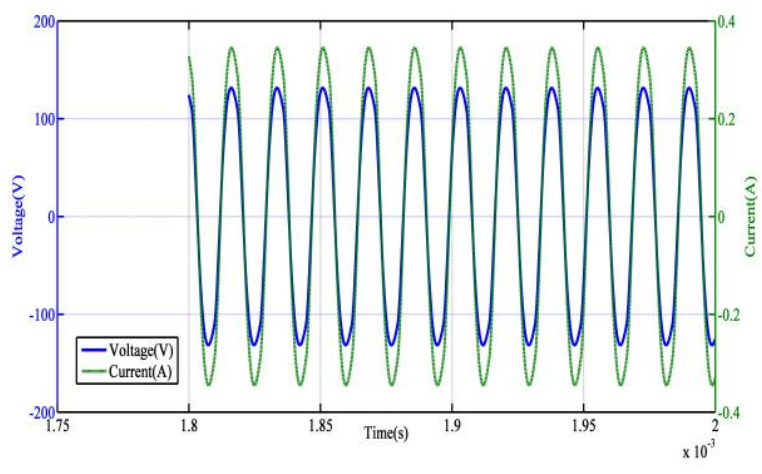

Fig. 8. Voltage-current of the lamp versus time at steady state operation

Figure 9 is represented to behave of the lamp at ignition. Especially the voltage signal has become sinusoidal signals varying its amplitude due to variable lamp resistant in 0.12 sec implemented the ignition. Sinusoidal the current and the voltage signals are obtained $0.12 \mathrm{sec}$ after lamp operating as to have constant amplitude in steady state. The high voltage at ignition able to be seen in that figure as well. This voltage is sufficient to ignite the lamp.

The Voltage, Vs, with square form, and Current, Is, with sinusoidal form, waveforms are presented in Fig.10. To expect from the resonant circuit is to minimize the phase difference between voltage and current of series branch. This expectancy is satisfied thanks to the given ballast circuit, designed in frequency domain.
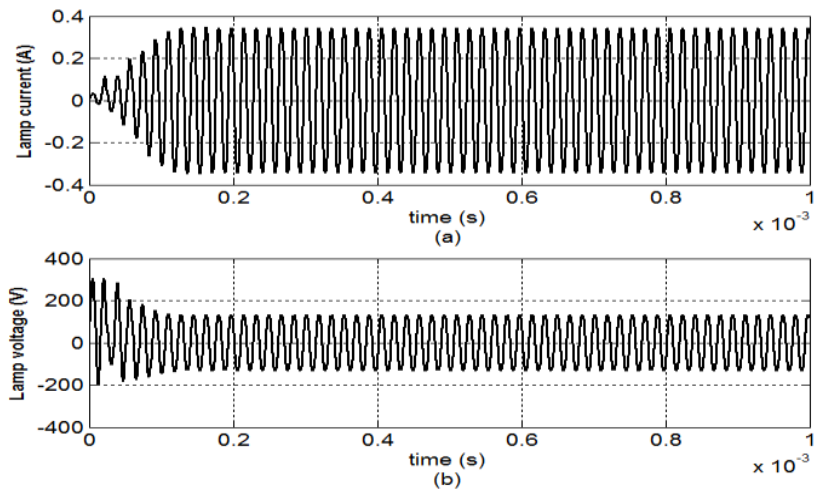

Fig. 9. The signals of the lamp versus time at ignition (a) Current of lamp vs time (b) Voltage of lamp vs time

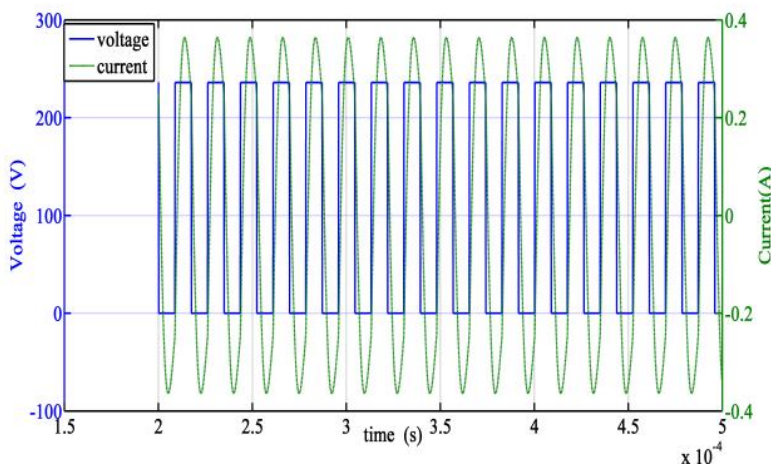

Fig. 10. Input Current and voltage waveforms after just switching process 


\section{Conclusion}

This paper presented that root placement method about to calculate the electronic ballast parameters through roots of the transfer function. Resonance tank circuit has been developed to base on operating point resistant of the fluorescent lamp through roots of frequency domain. Modelling of a dynamic resistance in software environment depends on the view of researchers. It can be seen that success of this in Fig.5. The method has simple mathematic calculations and is capable to provide accurate values, which can be employed in new types to ballasts. Whereas, previous studies about this topic were based on one of the circuit parameters or a function which is complex. This study is different to them from this aspect. In other words, this is innovator side of the method.

A critical issue that has been validated in this study is the starting voltage needed by fluorescent lamps is supplied. This can be seen from Fig. 6, 9. The phase difference between lamp voltage and current could be seen in Fig.8. It is nearly zero value. Simulation studies are made to observe success in virtual environment putting in process of integrated structure. To perform simulations of the integrated structure, comprising a component to have a dynamic resistance, and reaching the instantaneous value of the electrical signal is one of the success of this paper. The mathematical value of equation (1) and the dynamic resistance value obtained on the simulation environment is equal. This is another success of the simulation.

\section{References}

[1] U.S. Lighting Market Characterization, Building Technologies Program: 2010 U.S. Lighting Market Characterization, U.S. Department of Energy, 2012.

[2] I. Galkin, O. Teteryonok, I. Milashevski, "Weight and Size Estimation of Energy Efficient LED Ballasts" Elektronika Ir Elektrotechnika, vol. 120, No. 4, 2012.

[3] Mader U., Horn P., "A Dynamic Model for the Electrical Characteristics Lamp Model of Fluorescent Lamps" Industry Applications Society Annual Meeting, Conference Record of the 1992 IEEE, vol. 2, pp. 1928-1934, 04-09 October 1992.

[4] R. Verderber, "Electronic Ballast Improves Efficiency" Elec. Consultant, vol. 60, pp. 22-26, November 1980.

[5] J. R. Coaton, A. M. Marsden, Lamps and Lighting 4th Edition, 4 th ed. Routledge; November 1, 1996.

[6] J. Choi, "LED Driver Compatible with Electronic Ballast”, Ph. D. Dissertation, Dept. Elect. Eng. KAIST, 2013.

[7] Cheng C. A., Liang T. J., Chuang C. M., Chen J. F. “A Novel Method of Using Second-Order Lamp Model to Design Dimmable Fluorescent Lamps Electronic Ballast" Industrial Electronics Society, The 27th Annual Conference of the IEEE, pp. 1033-1037, 29-02 November/December 2001.

[8] Yu T. H., Wu L. M., Wu T. F., "Comparisons among SelfExcited Parallel Resonant, Series Resonant and Current-Fed
Push-Pull Electronic Ballasts", Applied Power Electronics Conference and Exposition, IEEE, vol. 1, pp. 421-426, February 1994.

[9] Istok R., "High Frequency Emissions of Electromagnetic and Electronic Fluorescent Lamps", IEEE International Symposium on Applied Computational Intelligence and Informatics , Romania, pp. 21-23, 21-23 May 2015.

[10] Sheeraz A.; Faizan A.; S. Riaz-ul-Hasnain; Duri S.; Sagib J. "Electronic Ballast Circuit Configurations for Fluorescent Lamps" Power Generation System and Renewable Energy Technologies (PGSRET), IEEE Conference Publications, pp. $1-8,2015$.

[11] A. Vitanza, R. Scollo, A. Hayes "Electronic Fluorescent Lamp Ballast”, Application Note, Microelectronics, 1999.

[12] Y. Ji, R. Davis, "Starting Performance of High-Frequency Electronic Ballast for Four-Foot Fluorescent Lamps" IEEE Transactions on Industry Applications, vol. 33, pp. 234-238, January/February 1997.

[13] R. A. Gupta, R. Agarwal, H. Soni, M. Ajay, "Design and Simulation of Single Stage High PF Electronic Ballast with Boost Topology for Multiple Fluorescent Lamp" vol. 2, pp. 323-331, November 2009.

[14] A. A. Mansour, O. A. Arafa, "Comparative study of $250 \mathrm{~W}$ high pressure sodium lamp operating from both conventional and electronic ballast", Journal of Electrical Systems and Information Technology, vol.1, pp: 234-254, December 2014.

[15] Wakabayashi F. T., Dantas F. D., Pinto J. O. P., Canesin C. A. "Fluorescent Lamp Model based on Equivalent Resistances, Considering the Effects of Dimming Operation" 2005 IEEE 36th Power Electronics Specialists Conference, pp. 1136-1141, 2005.

[16] Ribarich T. J., Ribarich J. J., "A new High-Frequency Fluorescent Lamp Model" IEEE Industry Applications Society Annual Meeting, St. Louis, Missouri, October, pp. 12-16, 1998.

[17] Moo C. S., Chuang Y. C., Huang Y. H., Chen H. N. "Modeling of Fluorescent Lamps for Dimmable Electronic Ballasts" Industry Applications Conference, San Diego, CA, vol. 4, pp. 2231 - 2236, 06-10 October 1996.

[18] J. David Irwin, R. Mark Nelms, Basic Engineering Circuit Analysis, 9. edition Wiley; (January 2, 2008)

[19] Shao J., Stamm T., "Cost Effective High Performance LED Driver Powered by Electronic Ballasts", IEEE Applied Power Electronics Conference and Exposition (APEC), Long Beacg, CA, pp. 3659-3662, 20-24 March 2016.

[20] Moo C. S., Cheng H. L., Lin T. F., Yen H. C. "Designing a Dimmable Electronic Ballast with Voltage Control for Fluorescent Lamp" Industrial Electronics, 1999. ISIE '99. Proceedings of the IEEE International, Bled, pp. 786 - 791, 1216 July 1999.

[21] Perdigão M., Saraiva E. S., "Electronic Ballast with Wide Dimming Range: Matlab-Simulink Implementation of a Double Exponential Fluorescent Lamp Model" Spanish Portuguese Congress on Electrical Engineering, Spain, pp. 1-6, 02-30 June 2005 . 